\title{
CHLOROGENIC ACID IMPROVED HIGH GLUCOSE INDUCED APOPTOSIS AND OSTEOGENIC DIFFERENTIATION IN MC3T3-E1 CELLS THROUGH ELIMINATING OXIDATIVE STRESS
}

\author{
XU TIAN ${ }^{\prime \prime}$, JIZHENG ZHANG', QIANG GUO ${ }^{2}$, GUANGYU WANG', ${ }^{1 *} \mathrm{WANG}^{2}, \mathrm{ZHIYONG} \mathrm{LI}^{2}$ and \\ JINGMING DONG ${ }^{1 *}$
}

'Department of Orthopaedics Institute, Tianjin Hospital, 406 Jiefangnan St., Tianjin 300211, China

${ }^{2}$ Baodi Clinical College of Tianjin Medical University (Orthopaedics Department), 8 Guangchuan Road, Baodi District, Tianjin 301800, China

\begin{abstract}
Long-term hyperglycemia affects bone metabolism and causes osteoporosis, the prevalence of diabetes-induced osteoporosis has prompted researchers to develop new biological therapies for its management. Chlorogenic acid (CGA) as an anti-oxidative, anti-inflammatory component has been found in lots of traditional Chinese medicine. In this study, we found that CGA improves high glucose (HG) induced inhibition of osteoblast differentiation and apoptosis of MC3T3-E1 cells through regulating oxidative stress. Detailly, alkaline phosphatase (ALP) activity and osteoblast viability of MC3T3-E1 cells were decreased but reactive oxygen species (ROS) production was increased by HG, and CGA increased ALP activity, osteoblast viability, and superoxide dismutase (SOD) activity but decreased ROS, the transcription of the genes ALP, Runx2, osteocalcin $(\mathrm{OCN})$ and protein of RUNX2 regulated osteogenic differentiation were also decreased by HG but increased by CGA supplementation. Protein and mRNA of Bcl-2 were decreased, but Bax and caspase- 3 were increased by HG, CGA further improved apoptosis of MC3T3-E1 cells through increasing expression of Bcl-2, but decreasing expression of Bax and caspase-3. These indicated that CGA improves the proliferation and differentiation of osteoblasts inhibited by high glucose, which may provide a perspective on the therapeutic role in the treatment of diabetic osteoporosis.
\end{abstract}

Keywords: anti-oxidative, apoptosis, chlorogenic acid, diabetic osteoporosis, MC3T3-E1 cells, osteoblast viability

Abbreviation: CGAC: chlorogenic acid, SOD: superoxide dismutase, HG: high glucose, ROS: reactive oxygen species, ALP: alkaline phosphatase, OCN: osteocalcin

Chlorogenic acid (CGA), a type of polyphenolic compound formed by esterification of caffeic and quinic acids, is the major active ingredient found in many traditional Chinese medicines such as Flos Lonicerae Japonicae and Eucommia ulmoides, and it is also abundant in some fruits, dietary vegetables, and daily beverages like coffee, beans, pineapple and apples $(1,2)$. CGA has been reported a wide range of diverse pharmacological effects, including anti-oxidative, anti-inflammatory, and anti-carcinogenic activities (2-4). As its natural and ubiquitous existence and its pharmacological effects such as anti-oxidative capacity, exploration of the clinical application on some common epidemics means great significance and prospect.

\# Xu Tian and Jizheng Zhang contributed equally to this article,

* Corresponding author: e-mail: Huntertianxu@163.com
Currently, 424 million people aged between 20 and 79 years worldwide are diabetic. The long-term metabolic disorder caused by diabetes leads to damage in multiple organs and systems (5). Meanwhile, long-term hyperglycemia caused by diabetes affects bone metabolism and causes osteoporosis, delayed or nonunion of fracture healing except for the cardiovascular and neurological complications (6). Diabetes-induced osteoporosis (DM-OS) is caused by chronic hyperglycemia, advanced glycated end products, and oxidative stress. The increase in the prevalence of DM-OS has prompted researchers to develop new biological therapies for the management of DM-OS (5). 
Many factors such as oxidative stress, hyperglycemia, weight loss were reported and involved in the occurrence and development of diabetic osteoporosis, the oxidative stress alters the bone remodeling process causing an unbalance between osteoclast and osteoblast activity, this can lead to metabolic bone diseases and contribute to the pathogenesis of skeletal system disorders including osteoporosis characterized by low bone mineral density and decrease in bone mass, which makes the bone weak and more prone to fracture (7-11), Many studies reported also the association between oxidative stress and diabetes, the oxidative stress increased significantly and induced various types of cells dysfunction in hyperglycemia (12). Given the important role of ROS and oxidative stress in bone turnover, there is considerable interest in the use of antioxidants in potential treatments for osteoporosis and bone inflammatory diseases. As the therapeutic agents to counteract oxidative stress-related diseases, plenty of polyphenols have been identified which are involved in the balance between the production and elimination of cellular free radicals (13).

In this study, we investigated the effect of CGA on the proliferation and differentiation of osteoblasts regulated by high glucose, which may provide a perspective on the therapeutic role of CGA in the treatment of diabetic osteoporosis.

\section{EXPERIMENTAL}

\section{Cell culture and treatment}

The mouse osteoblastic cells MC3T3-E1 were cultured in $\alpha$-MEM medium (GIBICO, USA) supplemented with $10 \% \mathrm{FBS}$ and $1 \%$ antibiotics (100 $\mathrm{U} / \mathrm{mL}$ penicillin and $100 \mathrm{U} / \mathrm{mL}$ streptomycin) at $37^{\circ} \mathrm{C}$ in a humidified atmosphere of $5 \% \mathrm{CO} 2,0.25 \%$ trypsin was used for cell passage.

\section{Measurement of ROS and superoxide dismutase (SOD) production}

$1 \times 10^{5}$ cells/well was plated in 24 -well plates into 3 repeat wells. After attached, the cultured cells were replaced with a new medium containing $4 \%$ FBS and normal $(5.5 \mathrm{mM})$ or high $(25.5 \mathrm{mM})$ amounts of glucose for days according to experimental design as well as with or without the various concentrations of CGA $(0,20,40$ and $80 \mu \mathrm{M})$ for the last $24 \mathrm{~h}$. The level of ROS was tested using 2,7-didichlorofluorescein diacetate (DCFH-DA) (Beyotime Biotechnology, China) according to the operation instructions, and the absorbance values were read using Synergy HTX microplate reader
(BioTek Instruments Inc., Winooski, USA) at 525 $\mathrm{nm}$. The SOD activity was detected by Total Superoxide Dismutase Assay Kit with WST-8 (Beyotime Biotechnology, China) according to the manufacturer's protocols, and the absorbance values were read at $450 \mathrm{~nm}$ using an automated microplate reader (BioTek Instruments Inc., Winooski, USA).

\section{Alkaline phosphatase (ALP) assay}

$1 \times 10^{5} /$ well MC3T3 E1 cells were cultured on 24-well plates into 3 repeat wells for $24 \mathrm{~h}$, the medium was replaced with a new medium containing $4 \%$ FBS and normal $(5.5 \mathrm{mM})$ or high $(25.5 \mathrm{mM})$ levels of glucose for 3, 5, 8, 10 and 15 days as well as with or without $\operatorname{CGA}(0,20,40$ and $80 \mu \mathrm{M})$ for the last $24 \mathrm{~h}$, and cultured. ALP activities in the culture supernatants were determined by measuring the hydrolysis of p-nitrophenyl phosphate according to the manufacturer's instructions (Beyotime Biotechnology, China).

\section{Cell viability assay (MTT)}

The proliferation of osteoblasts under high glucose conditions with or without CGA was estimated with MTT (3-(4, 5-dimethylthiazol-2-yl)-2, 5-diphenyltetrazolium bromide, $1 \mathrm{mg} / 1 \mathrm{ml}$ PBS). Briefly, $1 \times 10^{5}$ cells/well MC3T3 E1 cells were plated in 24-well plates into six repeat wells. After being cultured for $24 \mathrm{~h}$, the cells were serum-starved overnight in $\alpha$-MEM with $0.5 \%$ fetal bovine serum and then replaced with $4 \%$ serum medium containing normal $(5.5 \mathrm{mM})$ or high levels of glucose (25.5 $\mathrm{mM}$ ) for 3, 5, 8, 10 and 15 days and treated with different concentrations of CGA $(0,20,40$ and $80 \mu \mathrm{M})$ for the last $24 \mathrm{~h}$. After all the media was removed and cells were washed twice with phosphate buffer saline (PBS), the prepared MTT $(100 \mathrm{mg} / 100 \mathrm{~mL}$ of $\mathrm{PBS})$ reagent was mixed with the cells and incubated at $37^{\circ} \mathrm{C}$ for $3 \mathrm{~h}$. The formazan crystals formed were dissolved in dimethyl sulfoxide and the absorbance of color formation was measured at 570 $\mathrm{nm}$ using an automated microplate reader (Bio-Rad Laboratories, Inc., USA). The viable cell concentration is directly proportional to the intensity of the color produced.

\section{Western blot analysis}

After treatment, each group of cells was washed with precooled PBS three times and added cell lysate. After centrifuge, the supernatant was obtained and protein concentration was analyzed by BCA quantitative kit. The protein was separated by SDS-PAGE and transferred to PVDF membrane then incubated with $5 \%$ skimmed milk powder for 
A
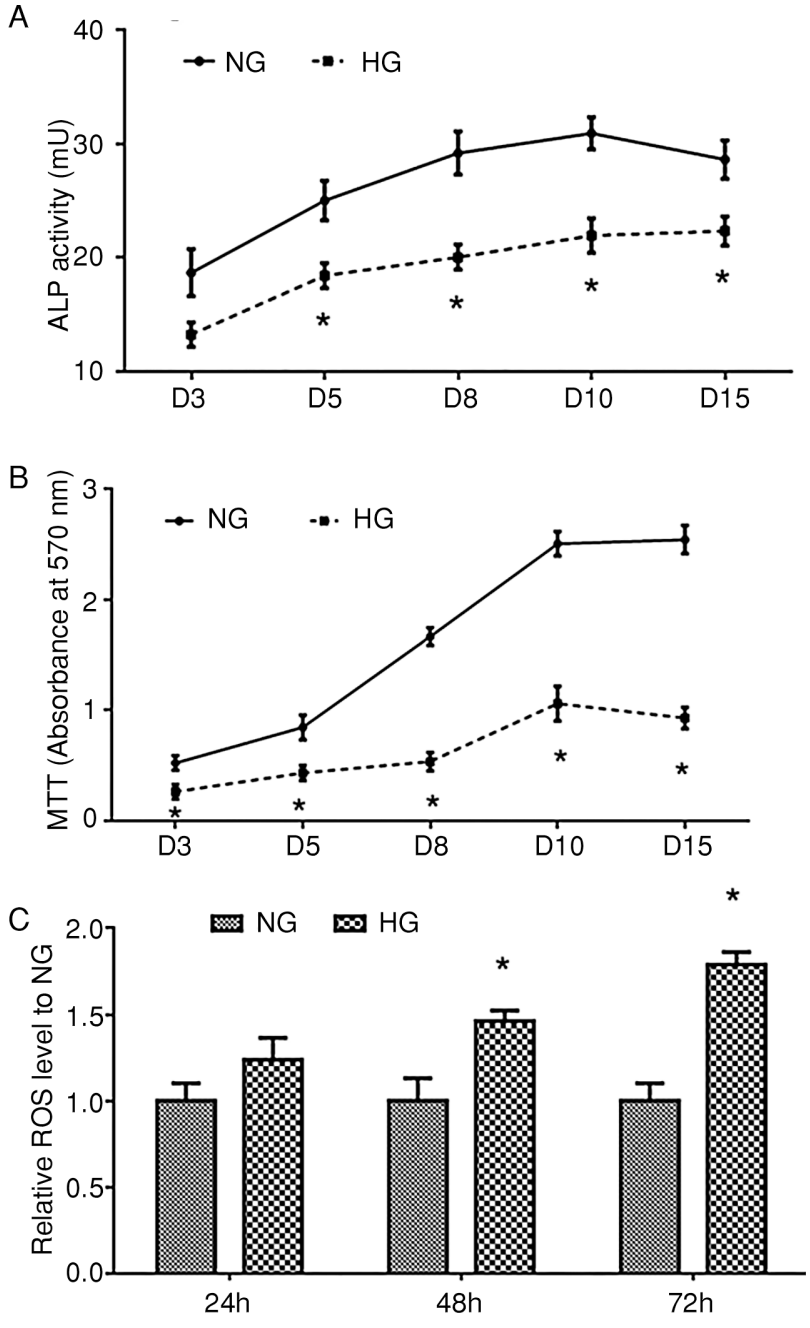

Figure 1. Effects of high glucose on osteogenetic differentiation, osteoblast proliferation and reactive oxygen species (ROS) production in MC3T3-E1 cells. (A) Alkaline phosphatase (ALP) levels and (B) MTT analysis in MC3T3-E1 cells under high glucose conditions (HG, $25.5 \mathrm{mM}$ ) were analyzed at day 0, 5, 8, 10, and 15. (C) Relative ROS level was measured under HG in MC3T3-E1 cells AT 0, 24, 48 and $72 \mathrm{~h}$. NG, normal glucose $(5.5 \mathrm{mM})$. Results are presented as the means $\pm \mathrm{SD}, \mathrm{n}=3$ experiments, ${ }^{*} \mathrm{p}<0.05$ compared to NG group.

$1.5 \mathrm{~h}$. After washing in TBST buffer, the PVDF membrane was incubated in antibodies against RUNX2 (Cell Signaling Technology, Inc., USA), Bcl-2, Bax, caspase-3 and GAPDH (ProteinTech Group, USA) at $4^{\circ} \mathrm{C}$ overnight. After washing, the membrane was incubated with anti-mouse or antirabbit secondary antibodies for $1 \mathrm{~h}$ at room temperature and detection was performed by an enhanced chemiluminescence system (ECL, Millipore).

Quantification of gene expression by reverse transcription-quantitative polymerase chain reaction (RT-qPCR)

Total RNA of MC3T3?E1 cells was extracted using TRIzol reagent (Invitrogen; Thermo Fisher
Scientific, Inc.). The concentration and purity of total RNA were evaluated by measuring the 260/280 $\mathrm{nm}$ ratios. Total RNA was used for RT reaction of $20 \mu \mathrm{L}$ with M-MLV system (Promega, USA), The mixture contained $5 \mu$ g total RNA, $1 \mu \mathrm{L}$ oligo (dT) 18 primer, $1 \mu \mathrm{L}$ dNTPs (10 mM), $4 \mu \mathrm{L} 5 \mathrm{X}$ M-MLV buffer, $1 \mu \mathrm{L}$ M-MLV, $1 \mu \mathrm{L}$ RNA enzyme inhibitors and DEPC water up to $20 \mu \mathrm{L}$. Total RNA was reverse transcribed into cDNA at $70^{\circ} \mathrm{C}$ for $5 \mathrm{~min}$, then at $42^{\circ} \mathrm{C}$ for $60 \mathrm{~min}$. PCR amplification was performed for 35 cycles with denaturation at $95^{\circ} \mathrm{C}$ for $30 \mathrm{~s}$, annealing at $60^{\circ} \mathrm{C}$ for $15 \mathrm{~s}$, and extension at $72^{\circ} \mathrm{C}$ for $15 \mathrm{~s}$, with a final extension at $68^{\circ} \mathrm{C}$ for 7 min after completion of all cycles. The primers used for PCR amplification were shown in Table 1. 


\section{Statistical analysis}

The statistical analysis was performed by SPSS 16.0 (SPSS LNC, USA). The results were expressed as $\mathrm{X} \pm \mathrm{SD}$ between the two groups, a T-test was used for the comparison of means, and single-factor variance was used for the comparison among multiple groups. A significant difference was considered when $\mathrm{p}<0.05$.

\section{RESULTS}

High glucose inhibits osteoblast viability and ALP activity but stimulates oxidative stress in MC3T3-E1 cells

ALP activity as one of the representative markers for an early stage of osteoblastic differentiation was reduced by high glucose (HG, $25.5 \mathrm{mM})$ at days 5, 8, 10, and 15 compared to normal glucose (NG, $5.5 \mathrm{mM})$ of mouse osteoblastic MC3T3-E1 cells (Fig. 1A). Osteoblast viability of MC3T3-E1 was inhibited by HG on day $3,5,8,10$, and 15 , the cell number of $\mathrm{NG}$ increased gradually from day 3 to day 10, but the cells grew slower in the HG-treated group than $\mathrm{NG}$ group (Fig. 1B). While HG stimulated intracellular ROS levels of MC3T3-E1 osteoblastic cells at $48 \mathrm{~h}$ and $72 \mathrm{~h}$ but did not influence intracellular ROS levels at $24 \mathrm{~h}$ (Fig. 1C).

\section{CGA improved oxidative stress stimulated by} High glucose in MC3T3-E1 cells

Intracellular ROS levels were tested using 2,7dichlorofluorescein diacetate, and we found that ROS stimulated by $\mathrm{HG}$ for $48 \mathrm{~h}$ were decreased by
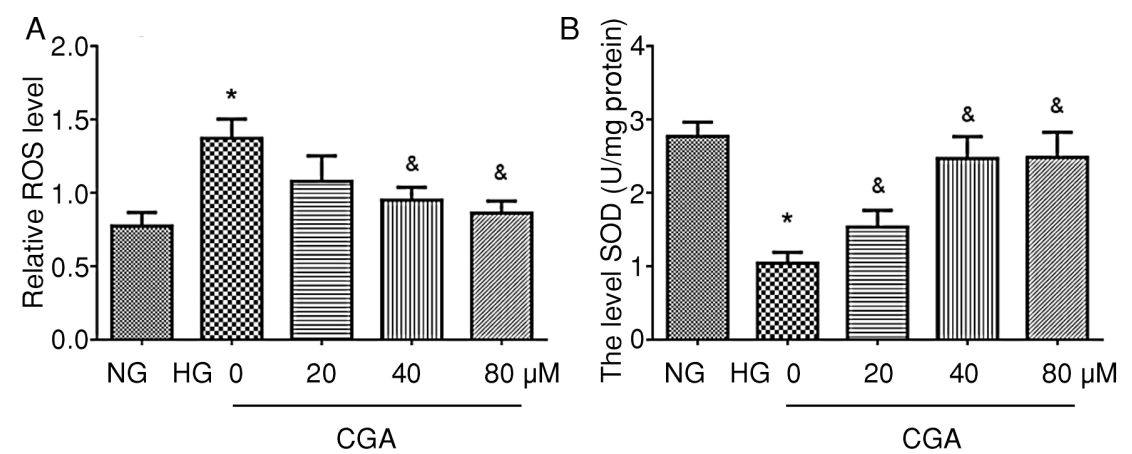

Figure 2. Effects of chlorogenic acid (CGA) on oxidative stress stimulated by HG. ROS (A) and SOD (B) levels of osteogenetic cells MC3T3-E1 treated with HG for 10 days, and with CGA for the last $24 \mathrm{~h}$ with concentration of $0,20,40,80 \mu \mathrm{M}$ was analyzed. Results are presented as the means $\pm \mathrm{SD}, \mathrm{n}=3$ experiments, ${ }^{*} \mathrm{p}<0.05$ compared to NG group, and $\mathrm{p}<0.05$ compared to $0 \mu \mathrm{M}$ CGA.

Table 1. Primer sequences for quantitative real-time polymerase chain reaction.

\begin{tabular}{|l|l|}
\hline Gene & \multicolumn{1}{c|}{ Primer sequences } \\
\hline Bcl-2 & Forward: 5'-GATGACTGAGTA CCTGAACCG-3' \\
\hline & Reverse: 5'-CAGAGACAGCCAGGAGAA ATC-3' \\
\hline BAX & Forward: 5'-TTGGAGATGAACTGGACAGC-3' \\
\hline & Reverse: 5'-CAG TTG AAG TTG CCA TCA GC-3' \\
\hline Caspase-3 & Forward: 5'-GACTGATGAGGA GATGGCTTG-3' \\
\hline ALP & Reverse: 5'-CAGTTGAAGTTGCCATCAGC-3' \\
\hline RUNX2 & $\begin{array}{l}\text { Forward: GAGAGCATGACCGATGGAT } \\
\text { Reverse: ATGTTTTGGTGGTCAGGAGG }\end{array}$ \\
\hline OCN & $\begin{array}{l}\text { Forward: ACCCTTCCAGACCAGCAGCAG } \\
\text { Reverse: TTCCGTCAGCGTCAACACCA }\end{array}$ \\
\hline GAPDH & $\begin{array}{l}\text { Forward: GAGGGCAATAAGGTAGTGAA } \\
\text { Reverse: CCATAGATGCGTTTGTAGGC }\end{array}$ \\
& Forward: TTGTCTCCTGCGACTTCAACA \\
& Reverse: GTGGTCCAGGGTTTCTTACTCC \\
\hline
\end{tabular}



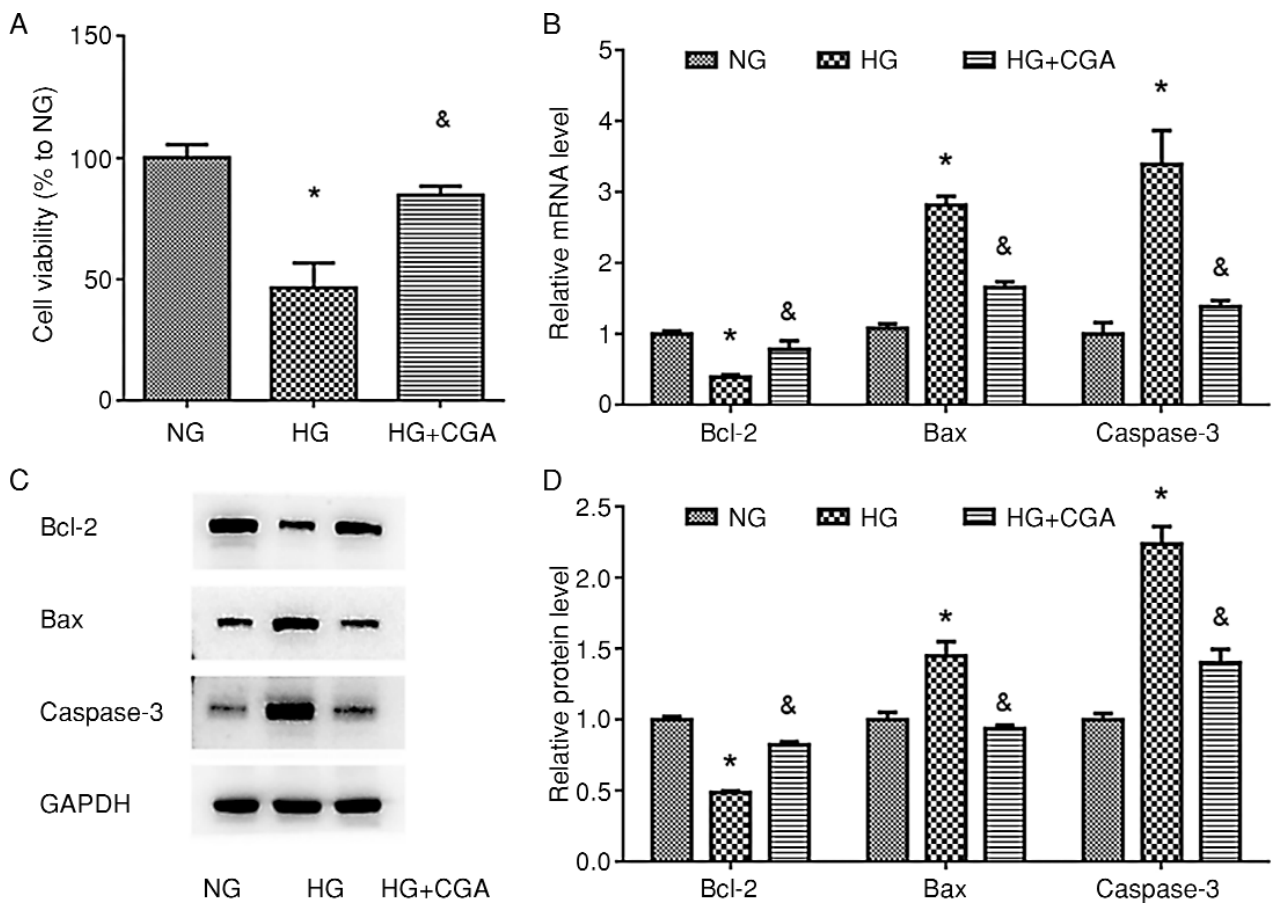

Figure 3. Effects of chlorogenic acid (CGA) on cell viability and the expression of apoptosis-related genes. Cell viability (A), mRNA (B) protein (C and D) levels of Bcl-2, Bax and Caspase-3 in osteogenetic cells MC3T3-E1 treated with HG for 10 days, and with $40 \mu$ M CGA for the last $24 \mathrm{~h}$ was analyzed. Results are presented as the means $\pm \mathrm{SD}, \mathrm{n}=3$ experiments, ${ }^{*} \mathrm{p}<0.05$ compared to $\mathrm{NG}$ group, and $\mathrm{p}<0.05$ compared to $0 \mu \mathrm{M}$ CGA.
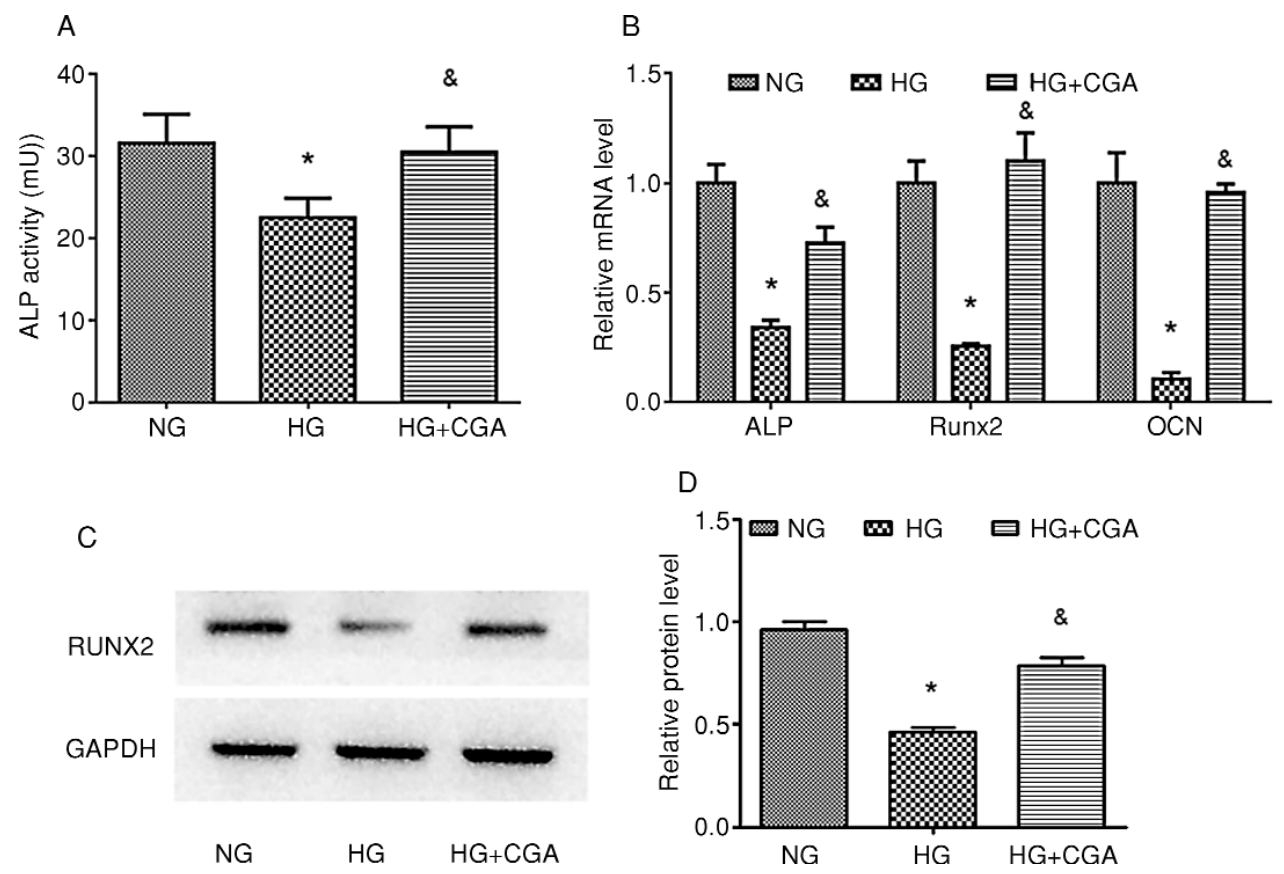

Figure 4. Effects of chlorogenic acid (CGA) on ALP activity and the expression of osteogenetic differentiation-related genes. ALP activity (A) and ALP, Runx2 and osteocalcin (OCN) mRNA levels (B) and protein level of Runx2 (C) of osteogenetic cells MC3T3-E1 treated with $\mathrm{HG}$ for 10 days, and with $40 \mu \mathrm{M}$ CGA for the last $24 \mathrm{~h}$ was analyzed. Results are presented as the means $\pm \mathrm{SD}, \mathrm{n}=3$ experiments, * $\mathrm{p}<0.05$ compared to NG group, and $\mathrm{p}<0.05$ compared to $0 \mu \mathrm{M}$ CGA. 
CGA of $40 \mu \mathrm{M}$ and $80 \mu \mathrm{M}$ but not $20 \mu \mathrm{M}$ in MC3T3-E1 osteoblastic cells (Fig. 2A). While SOD was inhibited by HG significantly, $20 \mu \mathrm{M}, 40 \mu \mathrm{M}$ and $80 \mu \mathrm{M}$ CGA significantly increased the level of SOD in MC3T3-E1 osteoblastic cells (Fig. 2B).

CGA regulated osteoblast viability and expression of apoptosis gene influenced by high glucose in MC3T3-E1 cells

Osteoblast viability of MC3T3-E1 was detected by the MTT method, and the cell viability inhibited by HG for 10 days was improved by CGA (Fig. 3A). Further, the genes regulating apoptosis were also influenced by HG but improved by CGA, mRNA and protein of $\mathrm{Bcl}-2$ was decreased by $\mathrm{HG}$ and recovered by CGA after $24 \mathrm{~h}$ treatment, also, CGA decreased transcription and translation of both Bax and Caspase-3 increased by HG (Figs. 3B, 3C, 3D).

CGA stimulating high glucose impaired osteogenic differentiation in MC3T3-E1 cells

ALP activity inhibited by HG on day 10 was increased by CGA in MC3T3-E1 cells (Fig. 4A). Further, the level of ALP, Runx2, and OCN mRNA and protein of Runx 2 regulated osteogenic differentiation were also decreased by $\mathrm{HG}$, while the addition of CGA to MC3T3-E1 cells treated 10 days with $\mathrm{HG}$ improved the reduction of these genes expression (Figs. 4B, C).

\section{DISCUSSION AND CONCLUSION}

Hyperglycemia has been proved to be associated with delayed bone healing, it also has the potential to affect a number of stages in the bone healing process, such as vascularization, clot formation, and even bone matrix synthesis, various tissues produce ROS under diabetic conditions (14-15). In our study, high glucose $(25.5 \mathrm{mmol} / \mathrm{L})$ significantly stimulated intracellular ROS production in MC3T3-E1. ROS consist of and lots of chemical entities such as oxygen free radicals, superoxide free radicals, hydrogen peroxide, singlet oxygen, nitric oxide (NO), and peroxynitrite (16). We discovered that CGA suppressed high glucose-induced ROS generation in MC3T3E1 cells. And as a ROS scavenger, the activity of SOD was also found to be inhibited by HG, CGA increased the activity of SOD inhibited by HG. As free radical scavengers and antioxidants, SOD has thus been used as protective and therapeutic agents against ROS-mediated injuries (17-18). This means that CGA can improve HG stimulated ROS through both inhibiting generation of ROS and increasing the scavenger of ROS by regulation of SOD.
It is now widely accepted that ROS can cause severe damage to DNA, proteins, and lipids, also lead to apoptosis, cell cycle arrest, and modulation of differentiation (19). Also, we found that high glucose inhibits osteoblast proliferation but this effect is reversed by treatment with CGA. Meanwhile, CGA prevented high glucose induced apoptosis by increasing $\mathrm{Bcl}-2$ whereas decreasing $\mathrm{Bax}$ and Caspase-3 expression in cells. It has been reported that high levels of ROS negatively affect bone development (20-21), and studies have shown that oxidative stress inhibits osteoblastic differentiation and induces osteoblast apoptosis (22-23). Given the important role of ROS and oxidative stress in bone turnover, there is considerable interest in the use of antioxidants in potential treatments for diabetic osteoporosis. In vivo and in vitro data have shown that antioxidants, directly and/or counteracting the effect of oxidants contribute to activation of osteoblast differentiation, mineralization process and reduction of osteoclast activity (24). Based on these, our study demonstrated that CGA effectively reduced high glucose induced oxidative stress and inhibited MC3T3-E1 cells apoptosis further promoted osteoblast proliferation and differentiation.

It is discovered in our study that CGA significantly rescued high glucose induced decreasing ALP activity and mRNA expression of ALP, RUNX2 and osteocalcin in MC3T3-E1 cells which indicated CGA could prevent inhibition of osteogenic differentiation by high glucose. The inhibiting effect of high glucose on osteoblast function is closely related to oxidative stress, ROS caused by high-level glucose was reported to lead to inhibition of the osteoblastic proliferation and differentiation, which eventually led to the damage of osteoblasts function (25-28). It has been reported that some antioxidants including GSH and NAC are able to stimulate osteogenic differentiation and restore osteoblastic mineralization through relieving oxidative stress (29). In STZ induced diabetic mice model, thioredoxin-1 overexpression attenuated osteopenia, which provided a novel therapeutic role of antioxidative protein in diabetic osteopenia (30). The different scientific evidences clarify that CGA demonstrates very valuable actions involving antiinflammation and anti-oxidant (11-13). There is also some evidence that CGA may affect lipid and glucose metabolism in genetic metabolic disorders (31). In addition, CGA has been shown to entail hepato-protective effects to protecting animals from lipopolysaccharide-induced damages or chemical injury (32). Dietary supplementation of CGA attenuated both the reduced plasma concentrations of 
high-density lipoprotein and the increased total cholesterol and plasma concentrations of low-density lipoprotein in rats (33). Clinical and scientific studies have implied that the ingestion of CGA can cause an anti-hypertension effect (34). Our study confirmed CGA as an antioxidant show a significant effect on restoring high glucose impaired osteoblastic function.

In conclusion, the results indicate that CGA as an antioxidant improved the proliferation and differentiation of osteoblasts via improvement of the oxidative stress impaired by high glucose, which shows a great therapeutic implication on diabetic osteoporosis of CGA.

\section{Conflicts of interest}

The authors declare no conflict of interest.

\section{REFERENCES}

1. Upadhyay R., Mohan Rao L.J.: Crit. Rev. Food Sci. Nutr. 53, 968 (2013).

2. Maalik A., Bukhari S.M., Zaidi A., Shah K.S., Khan F.A.: Acta Pol. Pharm. 73, 851 (2016).

3. Liu Y.J., Zhou C.Y., Qiu C.H., Lu X.M, Wang Y.T.: Mol. Med. Rep. 8, 1106 (2013).

4. Ye H.Y., Li Z.Y., Zheng Y., Chen Y., Zhou Z.H., Jin J.: Arch. Pharm. Res. 39, 989 (2016).

5. Mohsina S., Baniyasa M.M., AlDarmakia R.S., Tekes K., Kalász H., Adeghate E.A.: Expert Opin. Biol. Ther. 19, 937 (2019).

6. Napoli N., Chandran M., Pierroz D.D., Abrahamsen B., Schwartz A.V., et a1.: Nat. Rev. Endoerinol. 13, 208 (2017).

7. Lean J.M., Jagger C.J., Kirstein B., Fuller K., Chambers T.J.: Endocrinology 146, 728 (2005).

8. Manolagas S.C.: Endocr. Rev. 31, 266 (2010).

9. Banfi G., Iorio E.L., Corsi M.M.: Clin. Chem. Lab. Med. 46, 1550, (2008).

10. Mann V., Huber C., Kogianni G., Collins F., Noble B., et a1.: Bone 40, 674 (2007).

11. Baek K.H., Oh K.W., Lee W.Y., Lee S.S., Kim M.K., et a1.: Calcif. Tissue Int. 87, 226 (2010).

12. Brownlee M.: Nature 414, 813 (2001).

13. Vitaglione P., Morisco F., Caporaso N., Fogliano V.: Crit. Rev Food Sci. Nutr. 44, 575 (2004).
14. Baynes J.W., Thorpe S.R.: Diabetes 48, 1 (1999).

15. Dandona P., Thusu K., Cook S., Snyder B., Makowski J., et a1.: Lancet 347, 444 (1996).

16. Chong Z.Z., Li F., Maiese K.: Prog. Neurobiol. 75, 207 (2005).

17. Bafana A., Dutt S., Kumar A., Kumar S., Ahuja P.S.: J. Mol. Catal. B. Enzym. 68, 129 (2011).

18. Kwon M.J., Kim B., Lee Y.S., Kim T.Y.: J. Dermatol. Sci. 67, 81 (2012).

19. Bai X.C., Lu D., Bai J., Ke Z.Y., Li X.M., Luo S.Q.: Biochem. Biophys. Res. Commun. 314, 197 (2004).

20. Morikawa D., Norikawa D., Nojiri H., Kobayashi K., Watanabe K., et a1.: J. Bone Miner. Res. 28, 2368 (2013).

21. Omori K., Ohira T., Uchida Y., Ayilavarapu S., Batista Jr E.L., et a1.: J. Leukoc. Biol. 84, 292 (2008).

22. Zhou N., Hu N., Liao J.Y., Lin L.B., Zhao C., et a1.: Cell Physiol. Biochem. 36, 44 (2015).

23. Fatokun A.A., Stone T.W., Smith R.A.: Bone 39, 542 (2006).

24. Domazetovic V., Marcucci G., Iantomasi T., Brandi M.L., Vincenzini M.T.: Clin. Cases. Miner. Bone Metab. 14, 209 (2017).

25. Zhang Y., Yang J.H.: J. Cell Biochem. 114, 2595 (2013).

26. Choi E.M., Kim Y.H.: Cell Biol. Toxicol. 24, 225 (2008).

27. Balint E., Szabo P., Marshall C.F., Sprague S.M.: Bone 28, 21 (2001).

28. Botolin S., McCabe L.R.: J. Cell Biochem. 99, 411 (2006).

29. Ueno T., Yamada M., Igarashi Y. Ogawa T.: J. Biomed. Mater. Res. A. 99, 523 (2011).

30. Hamada Y., Fujii H., Kitazawa R., Yodoi J., Kitazawa S., et a1.: Bone 44, 936 (2009).

31. Zhang L., Chang C., Liu Y., Chen Z.: Med. Sin. 33, 281 (2011).

32. Shi H., Dong L., Jiang J., Zhao J., Zhao G., et a1.: Toxicology 303, 107 (2013).

33. Wan C.W., Wong C.N.Y., Pin W.K., Wong M.H.Y., Kwok C.Y., et a1.: Phytother. Res. 27, 545 (2013).

34. Zhao Y., Wang J., Ballevre O., Luo H., Zhang W.: Hypertens. Res. 35, 370 (2012).

\section{(C) 2020 by Polish Pharmaceutical Society. This is an access article under the CC BY NC license (c) (i) (8)} (http://creativecommons.org/licenses/by-nc/4.0/). 